\title{
Cross-sectional echocardiographic recognition of interruption of aortic arch between left carotid and subclavian arteries
}

\author{
J F SMALLHORN, R H ANDERSON, F J MACARTNEY \\ From The Hospital for Sick Children, Great Ormond Street, London
}

SUMMARY Interrupted aortic arch is a rare condition, usually lethal in early infancy without treatment. The only characteristic feature on conventional non-invasive investigation is peripheral pulse inequality, which indicates ductal constriction, and therefore may be absent or transient and preterminal.

We report the cross-sectional echocardiographic findings in seven patients with aortic arch interruption between the left carotid and subclavian arteries. Their ages were 1 day to 7 months (median $7 \cdot 5$ days). The arterial connection was concordant in four, double outlet right ventricle in two, and truncus arteriosus in one.

In each case the ascending aorta was small in comparison to the pulmonary trunk. From the suprasternal approach the ascending aorta could be seen to terminate in the left carotid artery, and the ductus to continue smoothly into the descending aorta, with no vestige of an aortic arch linking its ascending and descending portions. The left subclavian artery was seen to arise distal to the ductus in all but one patient. All four patients with ventriculoarterial concordance had pronounced subaortic stenosis caused by posterior displacement of the infundibular septum.

Cross-sectional echocardiography therefore provides the only accurate method of non-invasive diagnosis of this condition. It permits early treatment with prostaglandins to prevent ductal closure, a planned approach to cardiac catheterisation, and a further means of investigating the nature of subaortic stenosis in this condition.

Interruption of the aortic arch is a rare congenital anomaly, usually lethal in infancy, because of complete dependence of part of the systemic circulation on patency of the ductus arteriosus. ${ }^{2}$ Standard physical examination, chest radiography, electrocardiography, and M-mode echocardiography usually do not provide the means of specific recognition of the condition. Yet neonates with aortic arch interruption urgently need administration of prostaglandins to maintain duct patency, ${ }^{3-5}$ preferably before cardiac catheterisation is initiated.

Recent advances in imaging of the aortic arch by cross-sectional echocardiographic examination from the suprasternal notch ${ }^{6}$ led us to believe that aortic arch interruption should be diagnosable by this method. We therefore report the findings in seven

RHA and FJM are supported by the British Heart Foundation and, respectively, the Joseph Levy and Vandervell Foundations.

Accepted for publication 25 May 1982 patients with aortic arch interruption studied at this hospital over the past 14 months.

Subjects and methods

Between November 1980 and February 1982, seven infants were admitted to The Hospital for Sick Children who turned out to have aortic arch interruption, in each case between the left carotid and subclavian arteries. In three of these (Table), angiocardiography in another hospital had shown the diagnosis of aortic arch interruption, but in the remaining four, the diagnosis of aortic arch interruption was prospectively and correctly made by cross-sectional echocardiography. A combination of subcostal, precordial, and suprasternal approaches was used in each patient. Atrial situs was established from high kilovoltage filtered beam radiographs of the bronchi, and from echocardiography by short axis views of the abdomen to show 
Table Summary of findings in seven patients with interrupted aortic arch

\begin{tabular}{|c|c|c|c|c|c|c|c|c|c|}
\hline $\begin{array}{l}\text { Case } \\
\text { No. }\end{array}$ & Age & Sex & $A V$ connection * & $V A$ connection & $V S D$ & $\begin{array}{l}\text { Infundibular } \\
\text { septal } \\
\text { displacement }\end{array}$ & $\begin{array}{l}\text { Angio } \\
\text { preceded } \\
\text { echo }\end{array}$ & $\begin{array}{l}\text { Confirmationt } \\
\text { of intracardiac } \\
\text { anatomy }\end{array}$ & $\begin{array}{l}\text { Confirmation } \dagger \\
\text { of extracardiac } \\
\text { anatomy }\end{array}$ \\
\hline $\begin{array}{l}1 \\
2\end{array}$ & $\begin{array}{l}5 \mathrm{mth} \\
2 \mathrm{~d}\end{array}$ & $\begin{array}{l}M \\
M\end{array}$ & $\begin{array}{l}\text { Concordant } \\
\text { Concordant }\end{array}$ & $\begin{array}{l}\text { Concordant } \\
\text { Concordant }\end{array}$ & $\begin{array}{l}\text { Perimembranous outlet } \\
\text { Muscular outlet }\end{array}$ & $\begin{array}{l}\text { Posterior } \\
\text { Posterior } \\
\text { malaligned }\end{array}$ & + & $\begin{array}{l}\text { Necropsy } \\
\text { Angio }\end{array}$ & $\begin{array}{l}\text { Necropsy } \\
\text { Surgery }\end{array}$ \\
\hline 3 & $1 \mathrm{~d}$ & $\mathbf{F}$ & Concordant & Concordant & Muscular outlet & $\begin{array}{l}\text { Posterior } \\
\text { malaligned }\end{array}$ & - & Angio & Surgery \\
\hline 4 & $7 \mathrm{~d}$ & $\mathbf{F}$ & Concordant & Concordant & $\begin{array}{l}\text { Perimembranous } \\
\text { trabecular }\end{array}$ & Posterior & - & Necropsy & Necropsy \\
\hline 5 & $2 \mathrm{mth}$ & $\mathbf{F}$ & Concordant & DORV & $\begin{array}{l}\text { Inlet muscular and } \\
\text { doubly committed } \\
\text { subarterial (subaortic) }\end{array}$ & Absent & - & Angio & Angio \\
\hline 6 & $8 \mathrm{~d}$ & $\mathbf{M}$ & Concordant & DORV & $\begin{array}{l}\text { Perimembranous outlet } \\
\text { (subpulmonary) }\end{array}$ & Anterior & + & Angio & Surgery \\
\hline 7 & $7 \mathrm{mth}$ & $\mathbf{F}$ & Concordant & Truncus & Outlet subarterial & Absent & + & Necropsy & Necropsy \\
\hline
\end{tabular}

^All patients had situs solitus; †Most certain level given.

Angio, angiocardiogram; AV, atrioventricular; d, days; DORV, double outlet right ventricle; echo, echocardiogram; mth, months; VA, $\mathfrak{C}^{\circ}$ ventriculoarterial; VSD, ventricular septal defect.

the relation of the aorta and inferior vena cava to the spine. In addition, pulmonary venous and systemic venous connections were noted. The atrioventricular connection was established from subcostal fourchamber views of the atrioventricular junction, together with identification of ventricular morphology from the appearance of the atrioventricular valves and their chordal insertions. The ventriculoarterial connection was determined from study of the ventriculoarterial junction in subcostal long axis, precordial long and short axis, and suprasternal cuts.

Particular attention was paid to suprasternal notch examination. The transducer was initially placed in the suprasternal notch with its beam in the frontal plane of the body. In this cut, the right pulmonary artery was imaged in its long axis, lying above the left atrium, with the aorta appearing in its short axis. Next the transducer was rotated anticlockwise in an attempt to trace the aorta in its long axis. In this position the origin of the brachiocephalic and left subclavian arteries was sought. Particular care was taken to try and visualise that part of the aortic arch between the left carotid and left subclavian arteries together with the isthmus. Next the transducer was rotated clockwise until the aorta was visualised in its short axis. The scan head was then angled towards the right shoulder following the origin of the brachiocephalic artery into its carotid and subclavian branches. In this procedure care must be taken to trace the artery to the aorta, so that confusion with venous bifurcations does not occur. The transducer was then rotated anticlockwise, with angulation towards the patient's left shoulder. Initially the pulmonary trunk was visualised and then, as the scan head was angled further, the left pulmonary artery was seen. The persistent ductus arteriosus was imaged lying directly above the left pulmonary artery. Great care was taken to visualise both aortic and pulmonary ends of the patent ductus. $\frac{\mathbb{D}}{\mathbb{D}}$

The patients were studied with an Advanced Tech- $\frac{\vec{\Phi}}{\mathrm{C}}$ nology Laboratory mechanical sector scanner with a 3 $5 \mathrm{MHz}$ scan head. Images were recorded on $1 / 2$ or $3 / 4 \Phi$ inch video tape and analysed frame by frame using a $\vec{C}$ Sony Motion Analyser. Images were obtained fromo stop frames on the analyser using standard Tri-X film ${ }^{\text {? }}$ (ASA 400). Correlation with necropsy findings waso illustrated by use of specimens from the collections of The Hospital for Sick Children, Great Ormondo Street, the Cardiothoracic Institute, the Bromptono Hospital, and the Institute of Child Health, Univer- $\stackrel{\perp}{Q}$ sity of Liverpool.

\section{Results}

These are summarised in the Table. All patients had situs solitus and atrioventricular concordance. The ventriculoarterial connection was concordant in the?first four patients, and double outlet right ventricle in 3 two. Case 7 had truncus arteriosus, with separate origin of the right and left pulmonary arteries from? the truncus arteriosus. All of the abnormalities of $\circ$ connection were easily recognisable on cross-sectional echocardiography.

\section{AORTIC ARCH INTERRUPTION}

The first clue to the presence of interruption of the aortic arch in all patients was the discrepancy between N the size of the ascending aorta and pulmonary trunk $\sigma$ (compare Fig. 1 and Fig. 2). In most cases, the diameter of the ascending aorta was at the lower limit? of normal ${ }^{7}$ whereas the pulmonary trunk was huge. The size of the pulmonary trunk was such that it was possible in most patients to obtain a cut extending from the pulmonary valve or just above all the way $\widetilde{\Phi}$ along the pulmonary trunk and through the ductus $\frac{?}{\circ}$ 


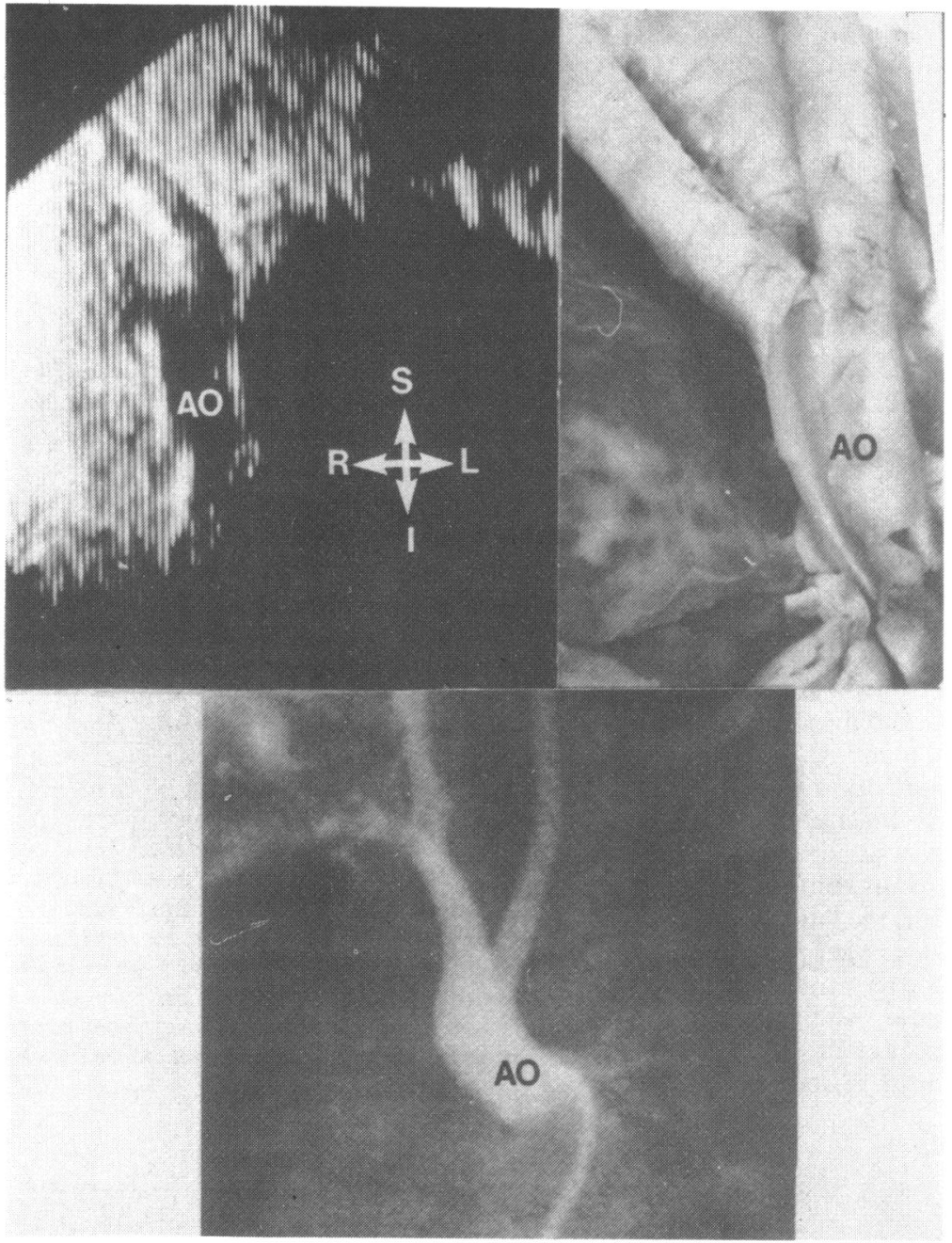

Fig. 1 The upper left picture is an echocardiogram from a case with an interrupted aortic arch distal to the left carotid. Note the origin of the brachiocephalic artery is also seen. The angiocardiogram is from the same patient. The necropsy specimen from a different case illustrates the anatomical features. AO, aorta.

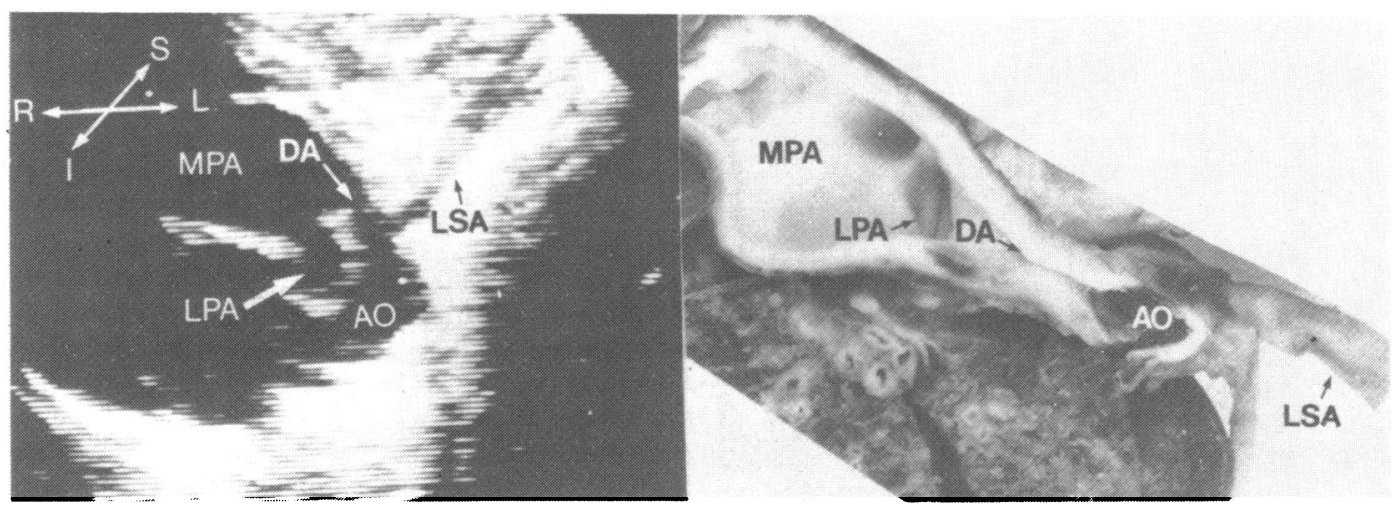

Fig. 2 The image on the left is an echocardiogram from a case with interruption showing the ductus arteriosus connecting the main pulmonary antery and descending aorta. Note the left subclavian artery arises from the descending aorta. In this cut there is no upper descending aorta visible. The specimen on the right is from a different case illustrating the morphological features. DA, ductus arteriosus; LPA, lefi pulmonary artery; $L S A$, lefi subclavian artery; MPA, main pulmonary artery; $A O$, aorta. 
arteriosus into the descending aorta (Figs. 2 and 3). This appearance might at first sight have been confused with that of a transposed aorta continuing into a normal aortic arch except that the left pulmonary artery (and in six patients the right pulmonary artery also (Fig. 3)) could be seen originating from the pulmonary trunk in this cut. The left subclavian artery was clearly identified apparently arising from the descending aorta (Fig. 2) in all but case 3 . The ductus arteriosus was a wide open structure with walls as smooth as the pulmonary trunk and descending aorta (Fig. 4) in the three patients aged 2 months old and above. In the remaining four patients, there was a greater or lesser degree of ductal constriction, manifested as intimal cushions projecting into the lumen (Fig. 3). Whether the ductus was wide open or constricted, however, the superior margin of the pulmonary trunk continued cleanly into the posterior margin of the descending aorta (Fig. 4).

The ascending aorta could be traced back to the aortic valve in all patients except the one with a truncus arteriosus, in whom the small ascending aorta was followed back to a huge common arterial trunk (Fig. 4) originating above a quadricuspid truncal valve. In all patients the origin of the brachiocephalic artery from the ascending aorta was identifiable (Fig. 1), though it was traced to its bifurcation (Fig. 5) in only four. In every patient, the left carotid artery gave the appearance of an index finger pointing towards the neck, with the carotid artery continuing smoothly on from the ascending aorta, with no suggestion of an aortic arch being present at all. Indeed, it was only possible in cases 3 and 4 to image the

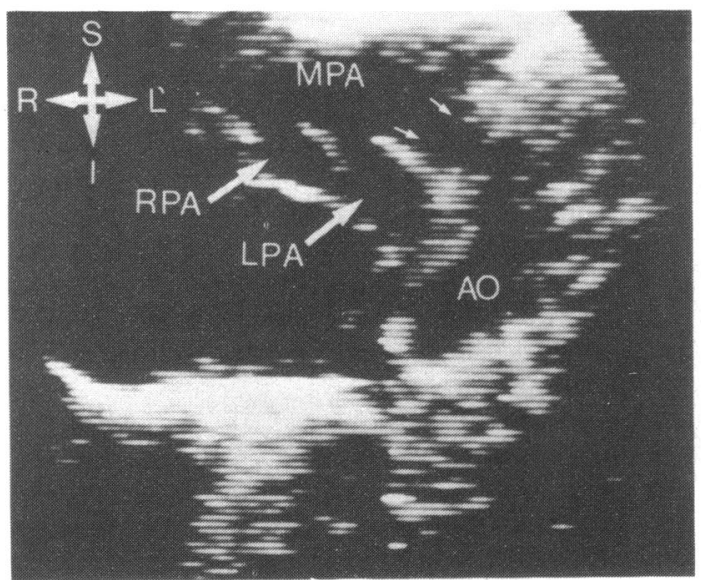

Fig. 3 This picture is from a patient with interruption of the aortic arch. The cut which is suprasternal shows the main, left, and right pulmonary arteries and the ductus in the same plane. Note the lumen of the ductus is irregular (arrows). RPA, right pulmonary artery (for other abbreviations see Fig. 1 and 2).

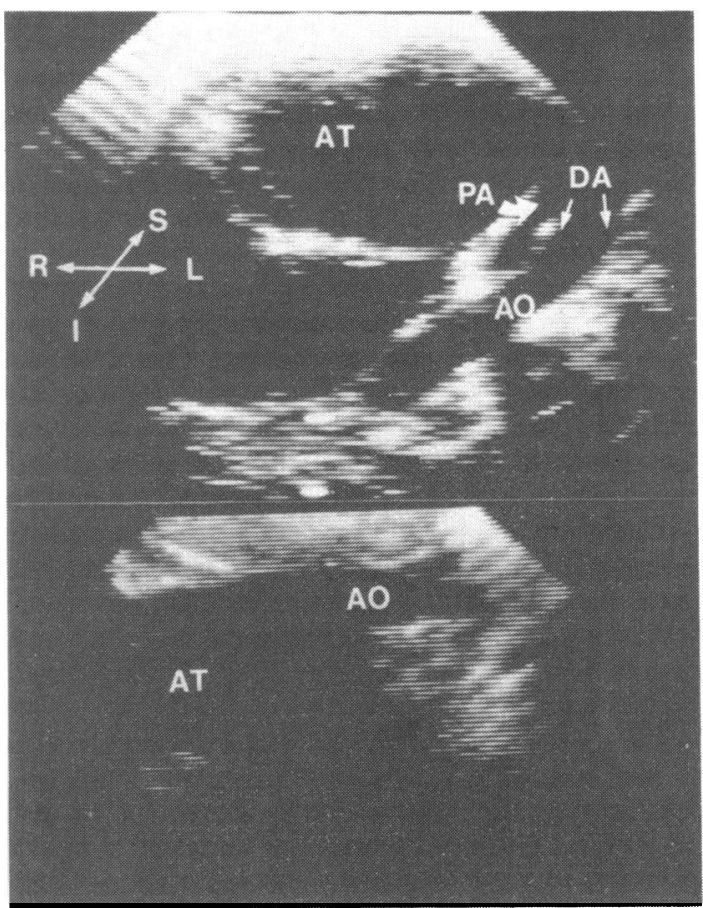

Fig. 4 The upper picture is from a case with interruption distal to the left carotid, associated with truncus arteriosus. Note the large ascending trunk and the ductus arteriosus connecting it to the descending aorta. The origin of the pulmonary artery is also seen. The lower picture is from the same case and shows the ascending aorta to its site of interruption. $A T$, ascending trunk; $P A$, pulmonary artery (for remaining abbreviations see Fig. 1 and 2).

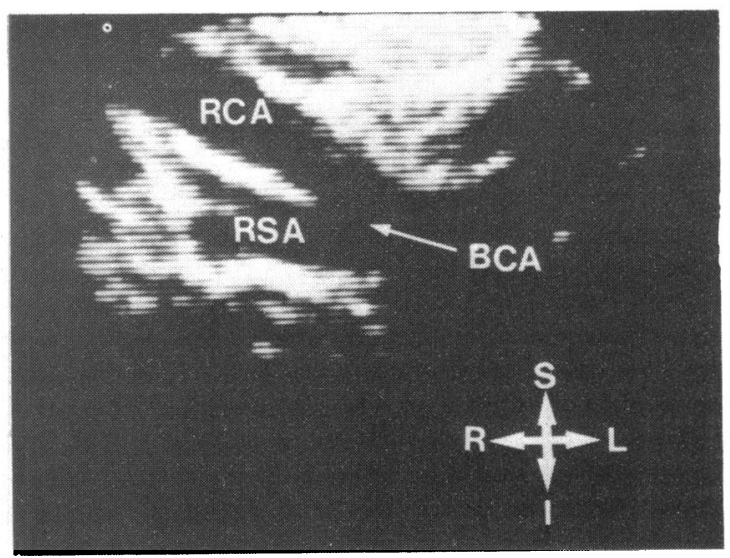

Fig. 5 The picture is a suprasternal view of the brachiocephalic artery in a case with interruption. Note the artery points to the right side (showing a left arch) and divides into the right carotid and subclavian branches. BCA, brachiocephalic artery; $R C A$, right carotid artery; $R S A$, right subclavian artery. 
ascending and descending aorta in the same plane (Fig. 6). The two were discontinuous and it was clear that the ascending aorta continued into the left carotid artery without attempting in any way to form a transverse segment of aortic arch.

\section{SUBSTRATES FOR SUBAORTIC OBSTRUCTION}

The relative smallness of the ascending aorta already mentioned extended to the aortic valve and subaortic region in all patients except the one with truncus arteriosus. In those patients with ventriculoarterial concordance, the long axis cut of the left ventricle showed posterior displacement of the infundibular septum of a pronounced degree in each case. In cases 2 and 3 , in whom a ventricular septal defect of muscu-

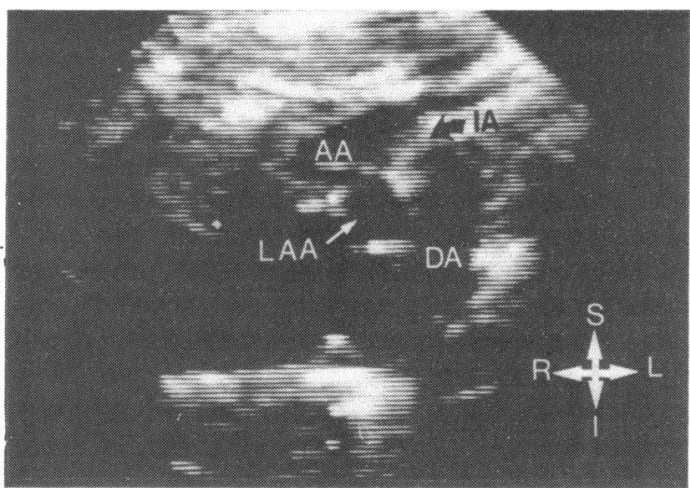

Fig. 6 This picture is from a case with interruption distal to the left carotid. Note the site of interruption is clearly seen, but in this patient the upper descending aorta can be visualised in the same cut, and is of a reasonable calibre. $A A$, ascending aorta; $D A$, descending aorta; IA, interrupted aorta; LAA, left atrial appendage. lar outlet type appeared small in the long axis cut, malalignment between the trabecular and infundibular septa was obvious. The superior portion of the infundibular septum lay in line with the trabecular septum, but as the infundibular septum was followed inferiorly, it curved posterior to the trabecular septum (Fig. 7). This malalignment was not so obvious in cases 1 and 4, where the ventricular septal defect was much larger and involved the perimembranous region. In each case, however, the posterior displacement of the infundibular septum gave the appearance of severe subvalvular aortic stenosis. Interestingly, in the first patient there was only a $5 \mathrm{mmHg}$ systolic gradient between left ventricle and ascending aorta, and in cases 2,3, and 4 there was no gradient at all between these sites. The subaortic region appeared crowded in case 6 , who had double outlet right ventricle with a subpulmonary ventricular septal defect, but no pressure was available in the ascending aorta. Thus, the only two patients in whom there was no echocardiographic suggestion of subaortic obstruction were the patient with a truncus, and the patient with double outlet right ventricle with a large subaortic ventricular septal defect extending to the junction between the aortic and pulmonary valves.

The only patient with an atrial septal defect was case 6, who had had a balloon atrial septostomy elsewhere. Pronounced bulging of the atrial septum from left to right was seen in cases 3 and 5. In the remainder the position of the atrial septum was more or less normal.

\section{Discussion}

Interruption of the aortic arch is a rare condition, occurring in 19 per million live births in the New
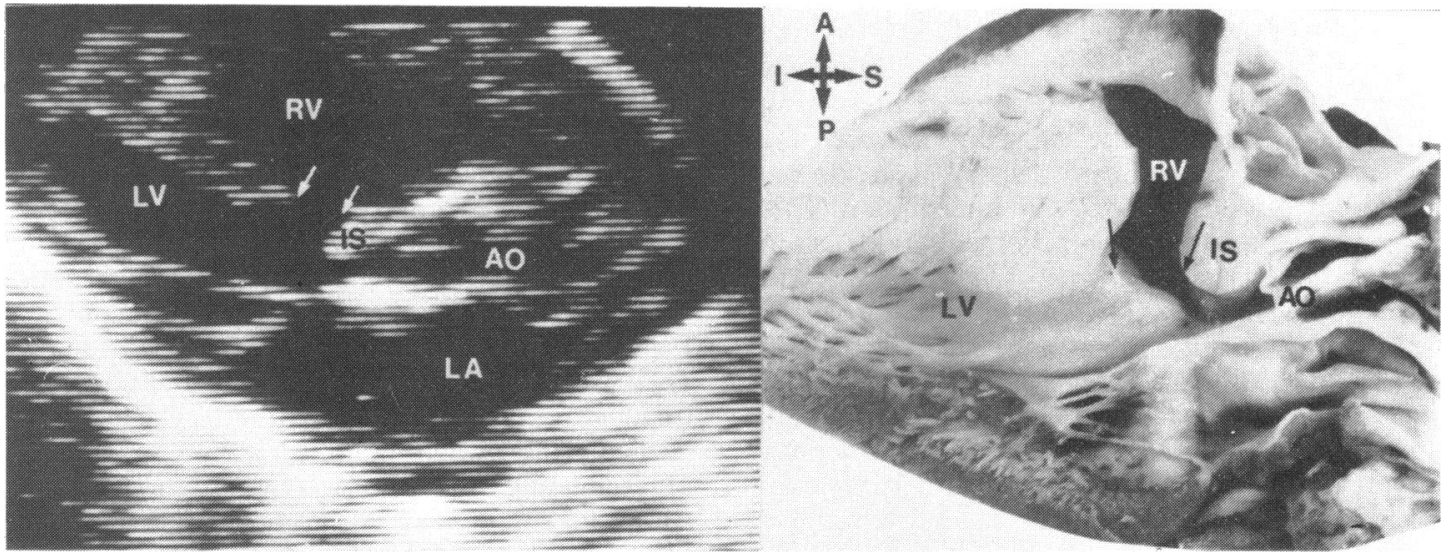

Fig. 7 The picture on the left is a parasternal long axis cut from a case with interruption. Note the posterior displacement of the infundibular septum into the left ventricular ouffow tract. The ventricular septal defect (indicated by the arrows) is muscular, and situated in the infundibular septum. The specimen on the right is cut in the same plane and shows the echocardiographic features, though it is from a different patient. AO, aorta; IS, infundibular septum; LA, left atrium; LV, left ventricle; RV, right ventricle. 
England regional infant cardiac program..$^{8}$ The sex incidence is equal. ${ }^{1}$ About $10 \%$ of patients have DiGeorge syndrome (thymic aplasia), and about $40 \%$ have serious associated non-cardiac congenital abnormalities. ${ }^{9}$ Nearly all patients present as neonates in severe intractable heart failure: $80 \%$ are admitted to a specialist hospital within 2 weeks and $93 \%$ by 1 month ${ }^{10}$ In necropsy series from children's hospitals, the median age at death was $4^{2}$ and $10^{1}$ days, respectively. Though this is bound to present a somewhat pessimistic view of the natural history, it does underline the exceedingly poor prognosis of this condition.

Interruption occurs very occasionally between the two carotid arteries. In the remaining cases interruption between the left carotid and subclavian arteries is slightly commoner than interruption distal to the left subclavian artery at the isthmus. ${ }^{1}$ By sheer chance, all the patients in this series had interruption distal to the left carotid artery.

Very occasionally, interrupted arch occurs as an isolated phenomenon, in which case descending aortic blood flow is maintained from systemic collateral circulation. ${ }^{11}$ In the vast majority of cases, however, particularly those presenting in the neonatal period, blood flow to the descending aorta is provided by a right to left shunt through the ductus arteriosus. This in turn depends upon there being pulmonary hypertension, and a pulmonary vascular resistance sufficiently high to ensure right to left shunting through the ductus arteriosus. In the majority of cases, pulmonary hypertension is maintained by the coexistence of a large ventricular septal defect without pulmonary stenosis. Much more rarely, an aortopulmonary window serves the same purpose. ${ }^{12} \mathrm{~A}$ left to right shunt through the ventricular septal defect tends to bring the saturations in the aorta and pulmonary artery close together, so that differential cyanosis on either side of the aortic arch interruption is extremely rare. ${ }^{13}$ Furthermore, while the ductus remains widely patent, the pulses distal to the interruption are well maintained. Indeed, pulse inequality has been mentioned as a distinctive physical sign ${ }^{10} 14$ only in more recent descriptions of aortic arch interruption. This is presumably because the sign is often only transitorily present. Such pulse inequality may take various forms, according to the site of interruption and the origin of the subclavian arteries. Ductal constriction invariably reduces the femoral pulses. If both subclavian arteries originate distal to the interruption, ductal constriction will in addition reduce the arm pulses, leaving only the carotid and superficial temporal pulses spared. More commonly, the left arm pulse is reduced by comparison with that in the right arm, indicating interruption distal to the left carotid with normal origin of the right subclavian artery. In theory, interruption between the brachiocephalic and left carotid artery should result in inequality between the two carotid or superficial temporal arteries. Whatever the precise nature of the pulse inequality, it $\stackrel{5}{?}$ reflects ductal constriction. If the patient survives, it $\bar{C}$ is because the ductus has reopened, and the pulse $\overline{\underline{\sigma}}$ inequality will have disappeared. If the ductus goes on $\frac{\bar{\sigma}}{\sigma}$ to close, the patient will become moribund and no $\stackrel{\mathbb{D}}{2}$ pulses will be palpable. Hence, unless this transitory physical sign is detected, there is no specific clue in $\vec{\circ}$ the standard investigation of the patient, including M-mode echocardiography, to suggest the presence of $\vec{\omega}$ interruption of the aortic arch. Yet the rapidity of $\stackrel{S}{S}$ normal neonatal ductal closure means that it is highly desirable to be able to make the diagnosis of aortic $\underset{\infty}{+}$ interruption before pulse inequality is found.

This study clearly shows that correct non-invasive $N$ diagnosis is possible with cross-sectional echocardiog- 0

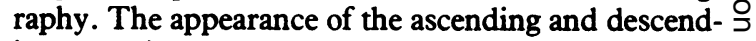
ing aorta in no way resembles a normal aortic arch, $\vec{c}$ even one affected by coarctation or isthmal hypop- $\mathbb{D}$ lasia. The "pointing finger" appearance of the left $\frac{\vec{D}}{\mathbb{D}}$ carotid artery corresponds to the characteristic "V- 3 sign" on angiocardiography. ${ }^{15}$ Both are the result of $\stackrel{\Phi}{\Phi}$ the ascending aorta continuing into the carotid artery $\overrightarrow{.}$ instead of into the aortic arch. The reason that the ${ }_{\infty}$ "V-sign" is not so well seen on cross-sectional ? echocardiography is that the carotid and brachiocephalic arteries lie in different planes, such that it is not possible to image the ascending aorta in continuity with the carotid artery, and in the same

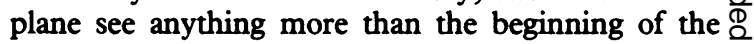
brachiocephalic artery (Fig. 1). Failure to demons- $\overrightarrow{\vec{F}}$ trate the ascending and descending aorta in the same $\frac{3}{3}$ cut, as occurred in all but two of our patients, may be $\bar{F}$ surgically relevant, since it suggests a wide gap between the two.

It is important to trace all the branches of the aorta, if at all possible, because it is not sufficient to guess the origin of an artery which is not seen. This is par- $\frac{5}{3}$ ticularly true of the subclavian arteries, which may be isolated, that is arising via a second ductus from the $\frac{O}{3}$ pulmonary artery ${ }^{16}$ or else much more frequently, in the case of the right subclavian, may originate 9 anomalously from the descending aorta. We were not $>$ successful in every case in identifying both subclavians, but believe this reflects lack of practice more or than an insoluble technical problem. We also know in the cases studied that the right subclavian arose $\mathcal{N}$ directly from the brachiocephalic artery. The left sub- $\omega$ clavian artery, when identified, gave the appearance of originating from the descending aorta. In sensuc strictu there is, of course, a segment of isthmus (transverse arch) between descending aorta and subclavian, + and this may be the substrate for the stenosis noted at ${ }^{2}$ the origin of the left subclavian in this type of inter- $\frac{\text { Tे }}{\mathbb{D}}$ ruption by Dische and colleagues. ${ }^{11}$ Such a stenosis 
was not observed in these patients.

Once the diagnosis is established by cross-sectional echocardiography, in the neonate, prostaglandin infusion should be started ${ }^{3-5}$ whether or not there is any evidence of ductal closure or constriction. This means that the patient can go to the cardiac catheterisation laboratory in the best possible condition, and that the invasive study can be carried out with emphasis on any features which have not been clearly shown by cross-sectional echocardiography. In this particular condition, we do not recommend surgery without cardiac catheterisation and angiocardiography, because there are still too many unanswered questions about what management is optimal.

The most striking of these problems is the role of subaortic stenosis. While the presence of subaortic stenosis caused by posterior displacement and rotation of the infundibular septum has clearly been described at necropsy, ${ }^{12} 17$ by angiocardiography, ${ }^{15}$ and now by cross-sectional echocardiography, in the majority of cases the anatomical abnormality has not been associated with a pressure gradient between the ventricles and the ascending aorta. This may in part be the result of a hitherto unmeasurable, but probably low, flow through the aortic valve. Though closure of the ventricular septal defect in such cases should not of itself increase the degree of left ventricular outflow tract obstruction, since the ventricular septal defect is upstream to the infundibular septum, postoperatively, the left ventricle will have to eject its entire stroke volume through the subaortic region, instead of shunting most of this left to right through the ventricular septal defect. It was Tyson and colleagues ${ }^{18}$ who originally suggested that in those patients with subaortic stenosis, the preferred operation was anastomosis of the pulmonary trunk to the descending aorta, with banding of the pulmonary arteries distal to the anastomosis, rather than any repair involving restoration of aortic continuity. Unfortunately, we do not know what the degree of subaortic obstruction was in those patients who have survived or not survived definitive surgery. It seems very likely, however, that some of the high mortality of surgery for this condition is the result of unrelieved subaortic stenosis. Cross-sectional echocardiography therefore provides not only a highly accurate means of making the diagnosis of aortic arch interruption, but also a further means of examining the subaortic region, which should, in the long run, help with optimal surgical management of this condition.

\section{References}

1 Van Praagh R, Bernhard WF, Rosenthal A, Parisi LF, Fyler DC. Interrupted aortic arch: surgical treatment. Am $\mathcal{f}$ Cardiol 1971; 27: 200-11.

2 Freedom RM, Bain HH, Esplugas E, Dische R, Rowe
RD. Ventricular septal defect in interruption of aortic arch. Am f Cardiol 1977; 39: 572-82.

3 Lang P, Freed MD, Rosenthal A, Castenada AR, Nadas AS. The use of prostaglandin $E_{1}$ in an infant with interruption of the aortic arch. $\mathcal{F}$ Pediatr 1977; 91: 805-7.

4 Heymann MA, Berman W Jr, Rudolph AM, Whitman V. Dilatation of the ductus arteriosus by prostaglandin $E_{1}$ in aortic arch abnormalities. Circulation 1979; 59: $169-73$.

5 Zahka KG, Roland JMA, Cutilletta AF, Gardner TJ, Donahoo JS, Kidd L. Management of aortic arch interruption with prostaglandin $\mathrm{E}_{1}$ infusion and microporous expanded polytetrafluoroethylene grafts. Am $\mathcal{F}$ Cardiol 1980; 46: 1001-5.

6 Sahn DJ, Allen HD, McDonald G, Goldberg SJ. Realtime cross-sectional echocardiographic diagnosis of coarctation of the aorta. A prospective study of echocardiographic-angiographic correlations. Circulation 1977; 56: 762-9.

7 Meyer RA. In: Meyer RA, ed. Pediatric echocardiography. Philadelphia: Lea and Febiger, 1978: 292.

8 Fyler DC, Buckley LP, Hellenbrand WE, Cohn HE. Report of the New England regional infant cardiac program. Pediatrics 1980; 65, suppl: 376-461.

9 Collins-Nakai RL, Dick M, Parisi-Buckley L, Fyler DC, Castaneda AR. Interrupted aortic arch in infancy. $\mathcal{f}$ Pediatr 1976; 88: 959-62.

10 Esplugas E. Interruption of the aorta-anatomical, clinical and angiocardiographic observations. In: Godman MJ, Marquis RM, eds. Paediatric cardiology Vol. 2: Heart disease in the newborn. Edinburgh, London: Churchill Livingstone, 1979: 187-95.

11 Dische MR, Tsai M, Baltaxe HA. Solitary interruption of the arch of the aorta. Clinicopathologic review of eight cases. Am $\mathcal{F}$ Cardiol 1975; 35: 271-7.

12 Moes CAF, Freedom RM. Aortic arch interruption with truncus arteriosus or aorticopulmonary septal defect. AFR 1980; 135: 1011-6.

13 Roberts WC, Morrow AG, Braunwald E. Complete interruption of the aortic arch. Circulation 1962; 26: 39 59.

14 Higgins CB, French JW, Silverman JF, Wexler L. Interruption of the aortic arch: preoperative and postoperative clinical, hemodynamic and angiographic features. Am $\mathcal{f}$ Cardiol 1977; 39: 563-71.

15 Neye-Bock S, Fellows KE. Aortic arch interruption in infancy: radio- and angiographic features. $A \mathcal{F}$ 1980; 135: 1005-10.

16 Barger JD, Creasman RW, Edwards JE. Bilateral ductus arteriosus associated with interruption of the aortic arch. Am f Clin Pathol 1954; 24: 441-4.

17 Moulaert AJ, Bruins CC, Oppenheimer-Dekker A. Anomalies of the aortic arch and ventricular septal defects. Circulation 1976; 53: 1011-5.

18 Tyson KRT, Harris LC, Nghiem QX. Repair of aortic arch interruption in the neonate. Surgery 1970; 67: 1006-10.

Requests for reprints to Professor F J Macartney, The Hospital for Sick Children, Great Ormond Street, London WCIN 3JH. 